\title{
Improvement of Andong Horseshoe Quality in Yogyakarta City to Support City Tourism
}

\author{
Alva Edy Tontowi*, Mochammad Noer Ilman, Dawi Karomati Baroroh \\ Department of Mechanical and Industrial Engineering, Faculty of Engineering, \\ Universitas Gadjah Mada, Yogyakarta, Indonesia
}

Submitted: March 09 ${ }^{\text {th }}$ 2019; Revised: February 06 ${ }^{\text {th }} 2021$; Accepted: February $10^{\text {th }} 2021$

\begin{tabular}{|c|c|}
\hline $\begin{array}{l}\text { Keywords: } \\
\text { horseshoe } \\
\text { small medium } \\
\text { enterprise } \\
\text { (SME) } \\
\text { Yogyakarta } \\
\text { redesign } \\
\text { layout }\end{array}$ & $\begin{array}{l}\text { Abstract The Zero Kilometer Point is an important route for andong horses in } \\
\text { Yogyakarta City. The renovation and replacement of road material with } \\
\text { andesite can cause horses to slip because the horseshoes have not been } \\
\text { adjusted to the new road material. If neglected, it can harm the horses and its } \\
\text { owners, reducing the tourism industry in Yogyakarta. On the other hand, } \\
\text { horseshoes demand is still met by small and medium enterprises (SME) without } \\
\text { a well-standardized system. After doing technical testing to the existing } \\
\text { horseshoe design, several alternative solutions were obtained for horseshoe } \\
\text { redesign (1) by adding rubber pads and (2) serrated without rubber pads. Based } \\
\text { on analysis and testing, it was found that horseshoe with the addition of rubber } \\
\text { by } 40 \% \text { was able to increase the friction value to } 0.54 \text { or } 10 \% \text { from the initial } \\
\text { condition. Besides improving the productivity and quality of SME horseshoe } \\
\text { products, several solutions should be considered, including ( } 1 \text { ) change the } \\
\text { layout design of SME by implementing } 5 \mathrm{~S} \text { lean six sigma principles and (2) } \\
\text { apply new methods/technology to maintain the standardization of horseshoe } \\
\text { product. Implementation of both solutions will guarantee not only the quality } \\
\text { product but also SME production. It is hoped that all the improvements that } \\
\text { have been made will increase the quantity and quality of horseshoe products. } \\
\text { Then it will also be able to improve the image of Yogyakarta City as a tourist } \\
\text { city. }\end{array}$ \\
\hline
\end{tabular}

\section{INTRODUCTION}

Special Region of Yogyakarta is well-known as one of Indonesia's regions, which has become a mainstay tourist destination for local and foreign tourists. In 2014, around 3,346,180 tourists visited Yogyakarta, or it increased by 17.90 percent compared to 2013 (krjogja.com, 2016). Apart from the Keraton and Malioboro, Zero Kilometer Point (KM 0) is one of the tourist icons in Yogyakarta City. However, since it was renovated and reopened, the KM 0 point has brought a new problem in the number of andong (traditional horse-cart) horses that have slipped (Figure 1). The road material is made of andesite stone and its convex shape makes the road more slippery and causes accidents to occur.

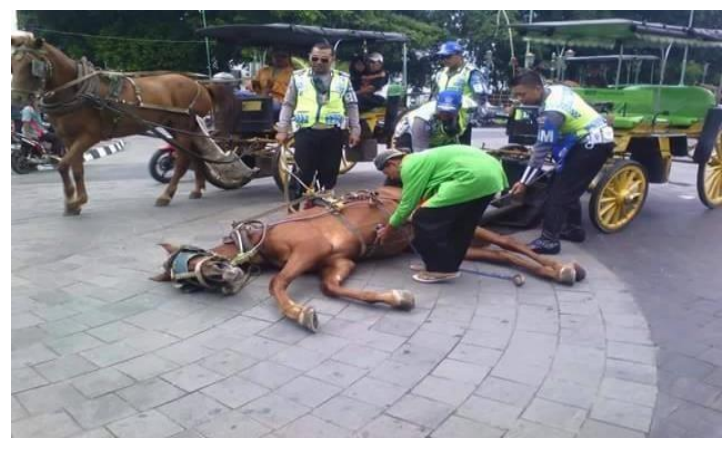

ISSN 2460-9447 (print), ISSN 2541-5883 (online)

${ }^{*}$ Corresponding author: Alva Edy Tontowi

Department of Mechanical and Industrial Engineering, Faculty of Engineering, Universitas Gadjah Mada, J. Grafika No. 2, Yogyakarta 55281, Indonesia

Email: alvaedytontowi@ugm.ac.id 


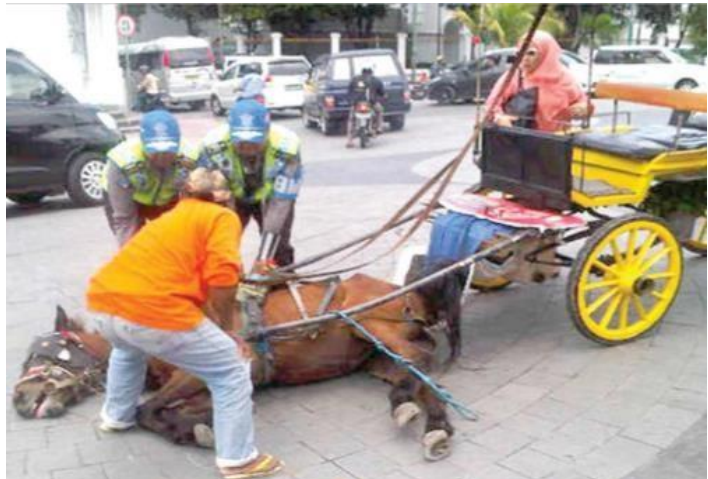

Figure 1. Horse slipping at Zero Kilometre Point of Yogyakarta City

In December 2015, the number of horses that slipped had reached ten (Solopos.com, 2016). The accident has a big impact on horses that can experience health problems with the risk of a relatively long healing time, even up to one year. On the other hand, the andong is a cultural expression that acts as one of the tourist city's pillars. The high number of accidents happening to andong horses has the risk of damaging the image of Yogyakarta as a tourist city. Based on preliminary observations to the $\mathrm{KM} 0$ area, we observed that the road conditions are classified as slippery and will get worse when it is raining/wet. One solution that can be applied is by evaluating the horseshoe design of the andong horse to adapt to the new road conditions. Changing the road at KM 0 point cannot be done due to the time and costs needed. The horseshoe itself is an important part that protects the horse's hooves from being eroded when walking on hard and rough surfaces. In Yogyakarta, there is only one horseshoe craftsman, namely Yuni Small and Medium Enterprise (SME), which is located in Dusun Pedes, Wates, Yogyakarta. This SME supplies the horseshoes demand for all areas in the Special Region of Yogyakarta. In a day, this SME capable of producing up to 100 horseshoes by using the forging method. This method is the oldest or most conventional method of metal formation (Martin, 2014).

After doing an initial survey of Yuni's SME, we found that the operational process of that SME was still quite optimal. However, the product was not standardized, and the workplace did not apply the $5 \mathrm{~S}$ principles (Figure 2). 5S is an approach introduced by Toyota company Japan to organize, order, clean, standardize, and continuously improve a work area (Agrahari et al., 2015). It is one of the efficiently working tools of lean manufacturing. Steps of the $5 \mathrm{~S}$ process are 1) Sort (Seiri), 2) Set in order (Seiton), 3) Shine (Seiso), 4) Standardize (Seiketsu), and 5) Sustain (Shitsuke). Without 5S principles, Yuni SME's productivity may become inefficient, whereas that SME is the main supply of horseshoes in the Special Region of Yogyakarta Province.
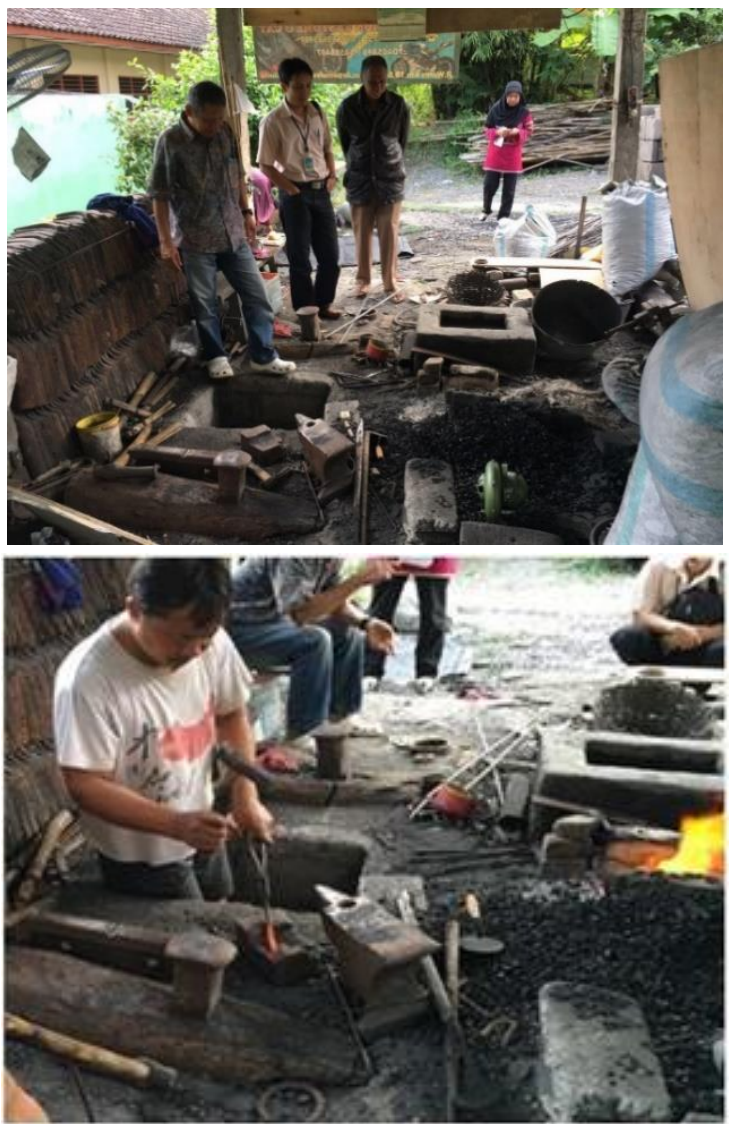

Figure 2. Initial conditions of horseshoe SME

The study's objective is to provide the optimal solution to solve the problem of andong horses slipping in the KM 0 area of Yogyakarta City by improving horseshoe product quality and improving the production system/method in the horseshoe SME. The remainder of this paper is organized as follows. Section 1 introduces the background and objectives of this study. Section 2 explains the method used in this study. Section 3 describes essential findings from technical testing of horseshoe product between existing design and several new designs (for redesign). This section also discusses several solutions that should be implemented in the horseshoe SME to improve the product and process efficiency. Then, the last section presents conclusions.

\section{METHOD}

In general, this study is carried out by making three approaches, which consist of:

a. Observation and direct interview

The direct observation method was carried out on the location of Zero Kilometer Point (KM 0) and to the Yuni SME horseshoe, which is the main supplier of horseshoes for the Special Region of Yogyakarta Province. Simultaneously, the interview method was carried out directly to several related parties, namely the andong associations, the andong horse owners, and the owner of Yuni's SME (horseshoe SME).

b. Technical testing 
This method was done to evaluate the existing design and new designs for horseshoe products. Several testing tests include (1) testing the hardness of the existing horseshoe, which was carried out at the Laboratory of Technical Materials, Engineering Faculty of Universitas Gadjah Mada (UGM); (2) testing the friction value of the existing horseshoe and the new design at the Laboratory of Product Design and Development, UGM (Figure 3); (3) testing the thickness of the existing horseshoe (before and after use) at the Laboratory of Production System and Process, UGM; (4) testing the existing horseshoe microstructure (before and after use) at the Laboratory of Technical Materials as seen in Figure 4; (5) direct testing of the new horseshoe design (redesign) selected to the field/real condition.

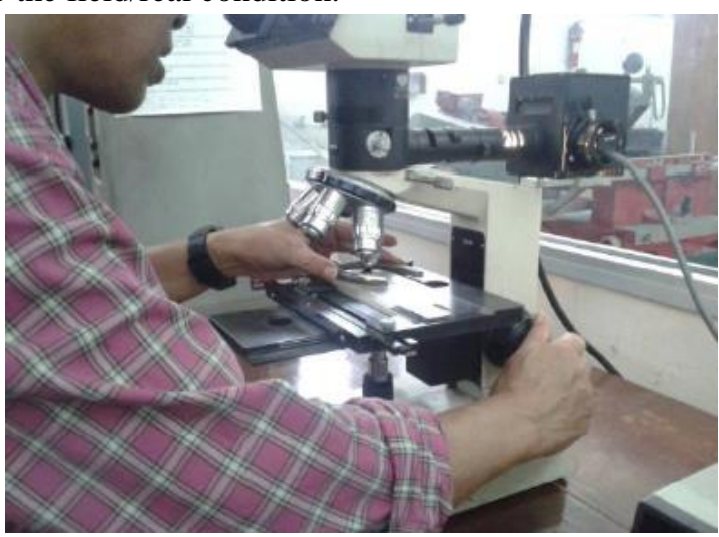

Figure 3. Microstructure analysis process

The hardness testing was done using the Brinell formula (equation 1), while friction testing was carried out by applying the mechanism as shown in Figure 4.

$$
H B=\frac{2 P}{\pi D\left(D-\sqrt{D^{2}-d^{2}}\right)}
$$

Note: $\mathrm{P}$ is load pressure test in N, D is steel ball diameter in $\mathrm{mm}$, and $\mathrm{d}$ is depression diameter in $\mathrm{mm}$.

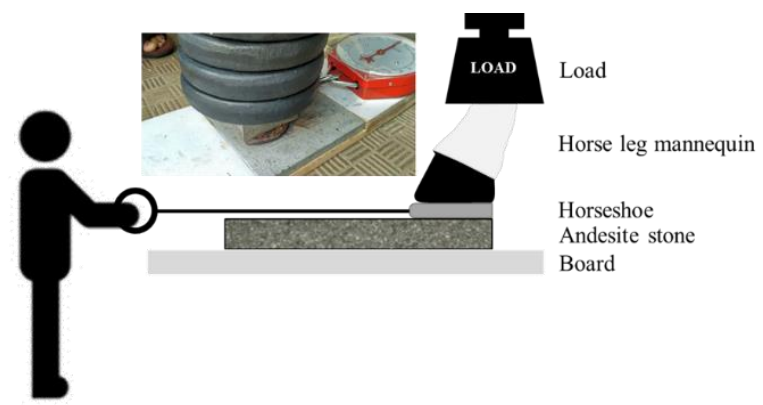

Figure 4. Friction testing mechanism

\section{c. Designing work systems}

This method is carried out to change Yuni's SME's work system by implementing $5 \mathrm{~S}$ principles (Seiri, Seiton, Seiso, Seiketsu, and Shitsuke). This principle tried eliminating activities/processes/conditions that are considered not optimal (or categorized as waste/non-added-value) to improve product quality and productivity of SME (Wardhana, 2013; Agrahari et al., 2015).

\section{RESULT AND DISCUSSION}

\subsection{Analysis of existing horseshoe design}

a. Hardness testing

We obtained that the hardness level of concrete iron (existing horseshoe) is $3.8 \mathrm{~N}$ by implementing the Brinell formula (Equation 1) with $\mathrm{P}=613 \mathrm{~N}, \mathrm{D}=2.5$ $\mathrm{mm}$ (steel ball), and $\mathrm{d}=1.368 \mathrm{~mm}$. One solution to increase horseshoe products' durability is by changing material with concrete steel (more durable) (Schneider and Chatterjee, 2015). However, after a direct interview with Yuni's SME owner, the replacement of horseshoe from iron to steel had been tried. Steel is indeed tougher and has a longer service life, but many horses slipped or fell when using steel shoes. Therefore, although concrete iron is classified as soft and wears easily, iron is more preferred than steel. This concept is the basis for designing a new horseshoe product. Concrete iron is still maintained as the horseshoe's main material. We tried to redesign the shape or add other materials, such as rubber, to reduce andesite slipperiness.

\section{b. Friction testing}

There are currently six sizes of horseshoe products in Yuni's SME (shown in Figure 5). The friction test on the existing horseshoe design was carried out on all sizes in two conditions of andesite (wet and dry testing). The friction testing mechanism is illustrated in Figure 4. After testing, the average friction force on wet andesite is 0.387 , and dry is 0.4475 (with the value of friction for each size shown in Figure 6).

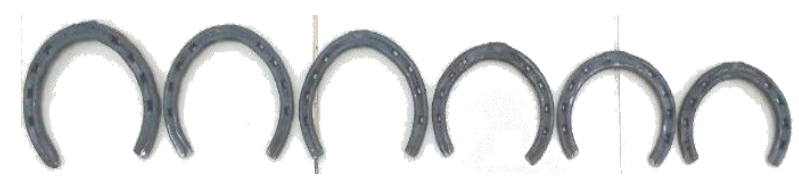

Figure 5. All sizes of the existing horseshoe product

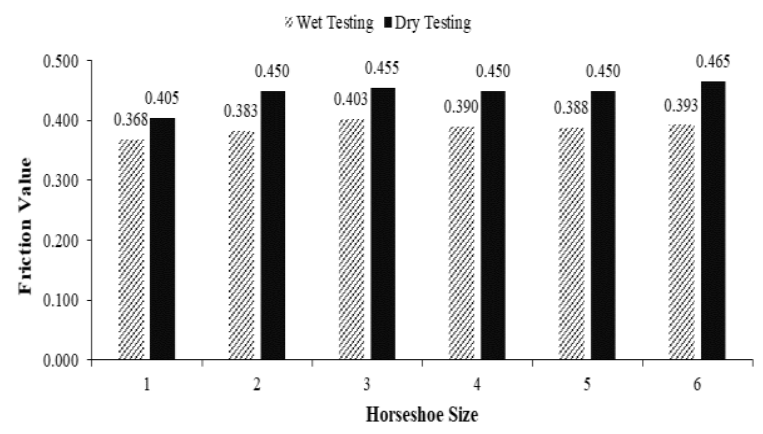

Figure 6. Friction testing result of the existing horseshoe for each size 


\section{c. Thickness testing}

This test was done by measuring horseshoe products' thickness before and after the usage for one week. Measurements were made using a micrometer in three points - the measurement points as shown in Figure 7. The thickness of the horseshoe before usage is $8.30 \mathrm{~mm}$ (point 1), $6.62 \mathrm{~mm}$ (point 2), and $7.40 \mathrm{~mm}$ (point 3), while after use for one week, the thickness changed to $3.67 \mathrm{~mm}, 3.58 \mathrm{~mm}, 5.93 \mathrm{~mm}$ for point 1, 2, 3 respectively. Based on the comparison results, it can be seen that points 1 and 2 have the most significant reduction in thickness. Because the horse's legs are running in a kicking motion so that the horseshoe is more easily worn or eroded in those points. Besides, point 1 is the outer part that causes the most direct contact with the road surface. Based on this thickness analysis, it can be used to determine the rubber pads' optimal location on the new design of horseshoe products, especially to increase the redesigned horseshoe's service life.
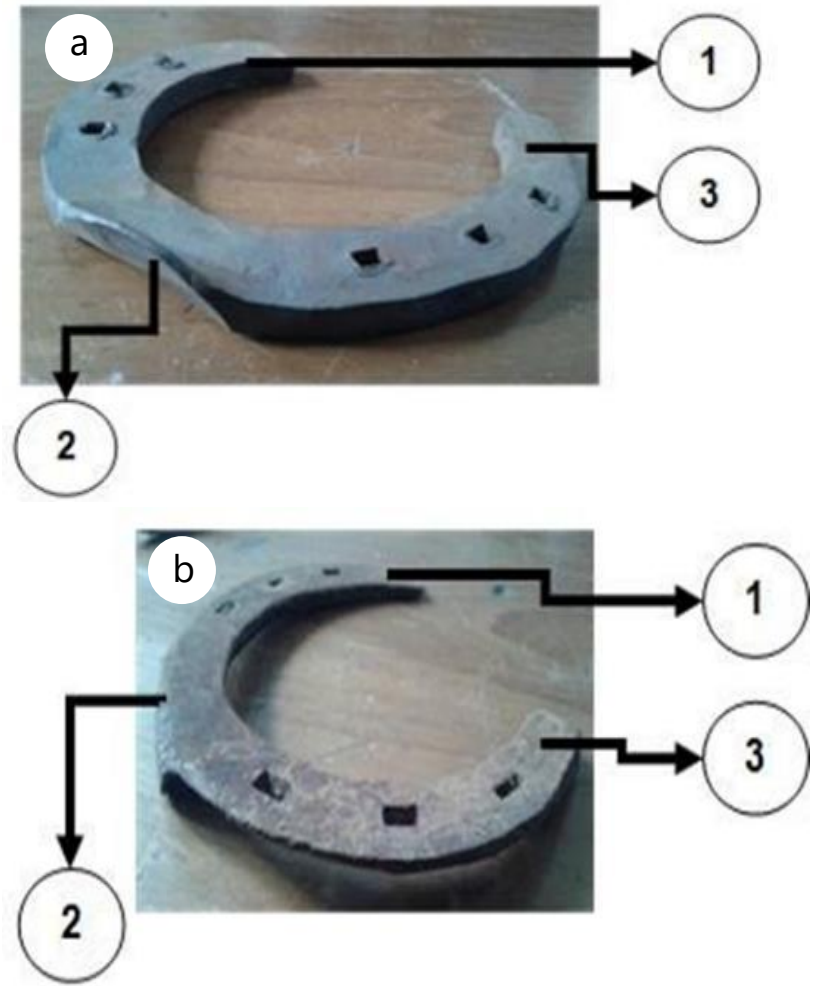

Figure 7. Thickness testing result of existing design: (a) before; and (b) after usage

d. Microstructure testing (before and after use)

Metal mechanical properties, including hardness, tensile strength, and toughness of metal, can be analyzed by considering the metal's microstructure analysis. Figure 8 showed the horseshoe material's microstructure before usage, while Figure 9 is after usage, which initial "a" for inner and "b" for outer.
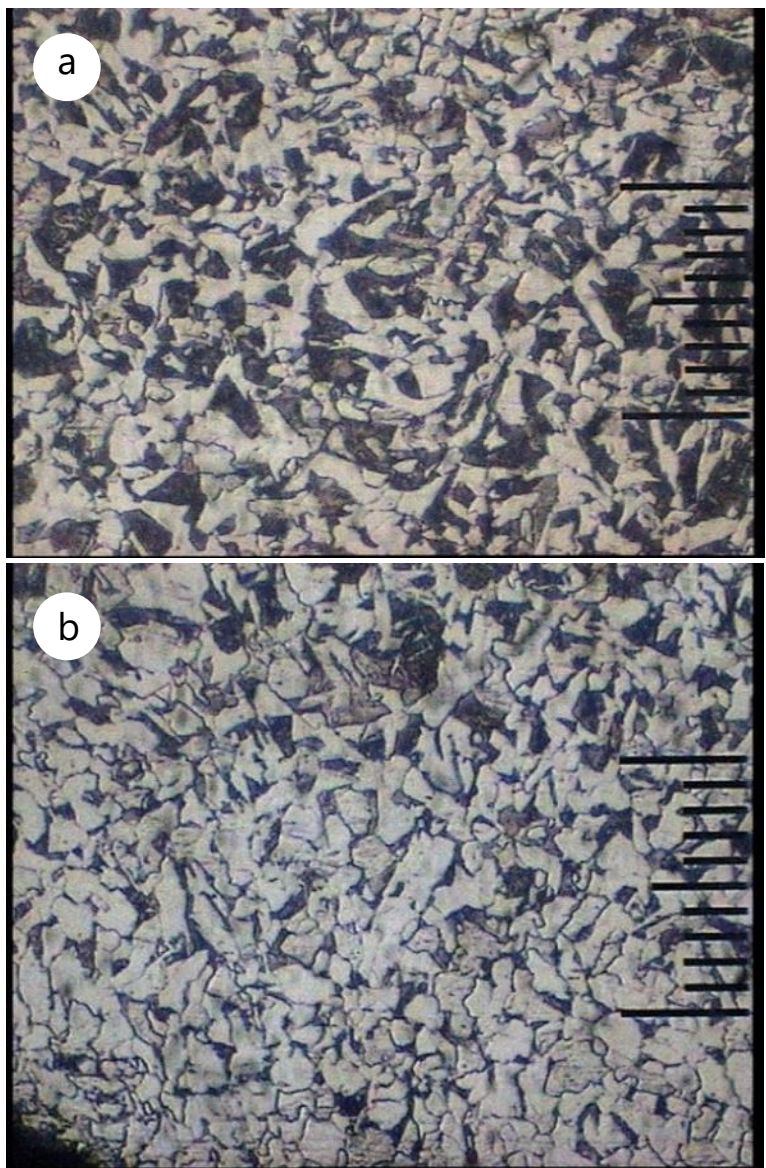

Figure 8. Microstructure analysis of horseshoe before usage

Figure 8 (a) shows the inner microstructure of the new horseshoe consisting of ferrite (light color) and pearlite (dark color), where the ferrite phase is relatively soft while the pearlite is harder. From the microstructure, it can be ascertained that the horseshoe material is made of medium carbon steel with a carbon content $(\mathrm{C})$ of around $0.3-0.4 \%$. Furthermore, the outer microstructure (Figure 8 (b)) shows that the ferrite phase (light color) is more dominant. This structure means an inhomogeneity in both composition and hardness where the outside is softer than the inside. As a result, horseshoes are prone to wear and tear.

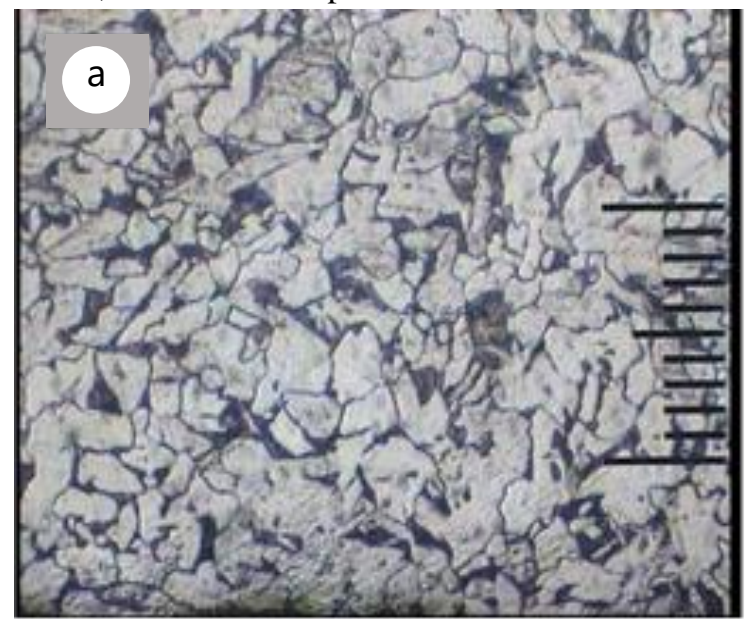




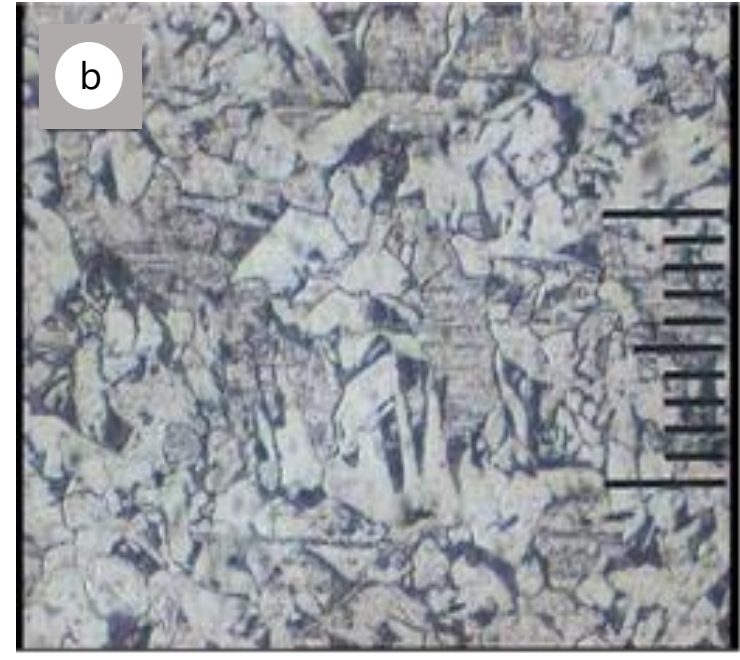

Figure 9. Microstructure analysis of horseshoe after usage

From Figure 9, it can be seen that the amount of ferrite (light color) is more than pearlite (dark color), so it is confirmed that this type of material is softer than the material in Figure 8. It is necessary to increase hardness through surface treatment such as carburizing, nitriding, or cyaniding to improve wear resistance to the horseshoe product. Of the three methods, carburizing is a more practical method. Carburizing is done by placing the horseshoe material in a stainless-steel box and then sprinkling it with charcoal powder and about $5 \% \mathrm{BaCO}_{3}$ (barium carbonate) as an activating carbon (BOC, 2016; and Kwietniewski et al., 2013). As a result, the $\mathrm{C}$ content on the surface of low carbon steel becomes high so that the hardness increases, which means that the horseshoe's wear resistance increases.

\subsection{Re-designed horseshoe product}

Based on the several technical testing results of the existing horseshoe product, redesign of the horseshoe is one of the best solutions to solve this problem. There are two alternative designs which offered including a) a horseshoe with rubber pads as design $\mathrm{A}$ and (b) a serrated horseshoe without rubber pads as design B (can be seen in Figure 10 and Figure 11).

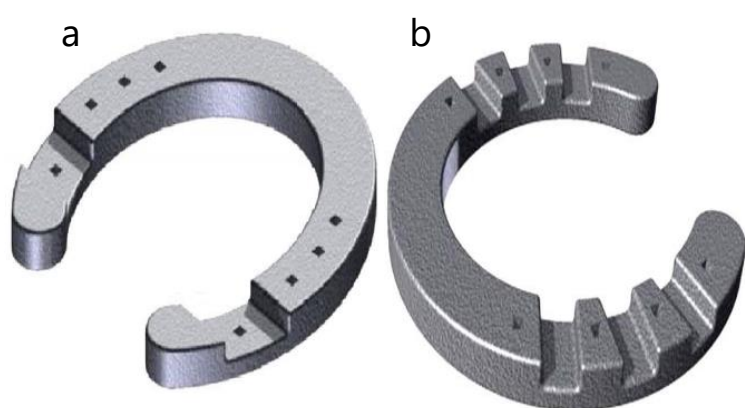

Figure 10. 3D model of horseshoe redesign: (a) design $A$ (with rubber pads); and (b) design $B$ (serrated/ without rubber pads)

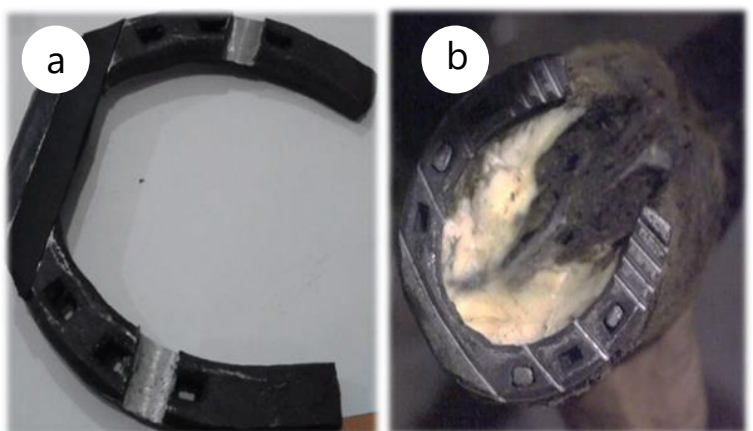

Figure 11. The prototype of horseshoe redesign: (a) design A; and (b) design $B$

For design A, it will analyze the optimal composition of rubber pads. The target is to increase the horseshoe friction coefficient with andesite stones by $10 \%$. Because of the technical testing results, it was found that an increase of $10 \%$ can increase the force by $10 \mathrm{~N}$, thus reducing the slipperiness of the horseshoe in andesite stones.

\subsection{Analysis of redesigned horseshoe product}

Several tests were carried out on horseshoes that had a rubber pad (design A). The test evaluates design A by implementing rubber composition ranging from $0 \%$ to $100 \%$ rubber at the bottom of the horseshoe in wet and dry conditions of andesite stones (Figure 11). After testing, it was found that the optimal horseshoe according to the target was a horseshoe with a $40 \%$ rubber composition. That composition can increase the friction value by $10 \%$ in dry conditions and $15 \%$ in wet conditions (Figure 12). Furthermore, testing was carried out on horseshoes with $40 \%$ rubber pads (design A) and horseshoes serrated without rubber pads (design B).

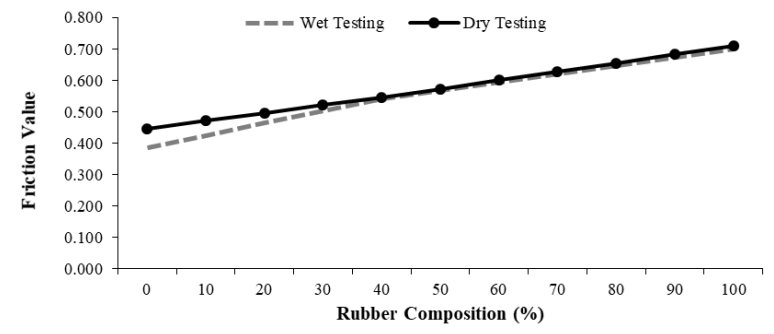

Figure 12. Testing of design A with rubber composition (0$100 \%)$

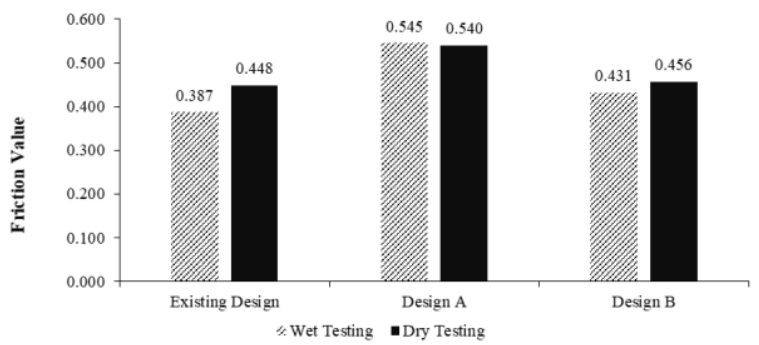

Figure 13. Comparison of the friction value among three designs 
Based on Figure 13, it can be seen that the horseshoe with the addition of $40 \%$ rubber pads (design A) has the highest friction value on the andesite surface compared to the other two horseshoes designs. It shows that this horseshoe design can be continued to direct field testing to determine the level of movement stability of the horse cart. Here is a picture of the selected horseshoe prototype - design A (Figure 14). After conducting field experiments using the selected design, it was found that the addition of rubber was able to increase the friction value between the poultice and the road so that it was not slippery and made the horse cart run stably.

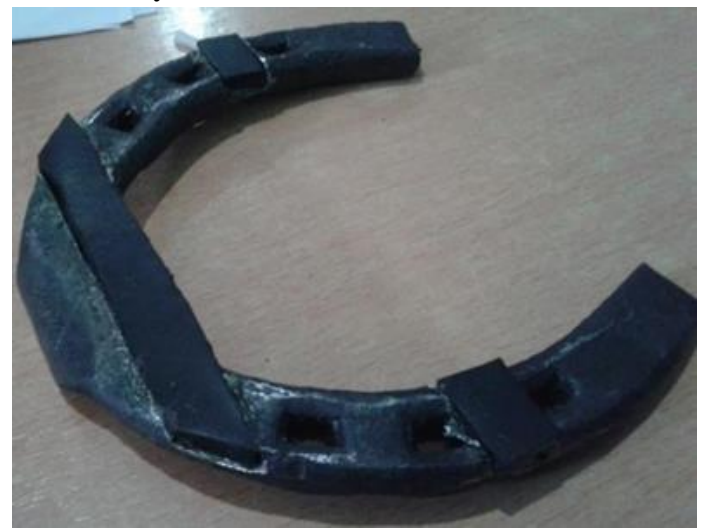

Figure 14. A prototype of optimal design of horseshoe $(40 \%$ rubber pads)

\subsection{Work system design for the horseshoe SME}

Based on the results of preliminary observations and direct interviews at Yuni's SME, the team will implement two alternative solutions to improve the work system at SME to increase the quantity and quality of products, including:

a. Improvement of work layout

The initial layout was still not well organized, and the absence of $5 \mathrm{~S}$ work principles was the focus of improvements suggested for this study. The following is a $3 \mathrm{D}$ design of the proposed layout design for horseshoe's SME (Figure 15).

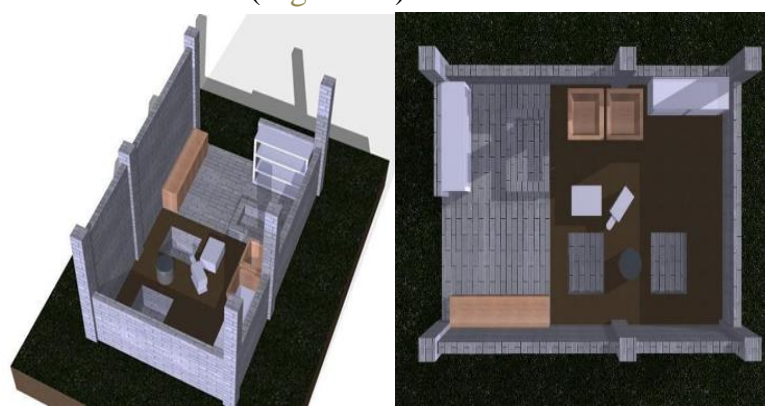

Figure 15. New layout design of horseshoe's SME

The renovations were done by making the walls to a height of about $80 \mathrm{~cm}$ to prevent the incoming wind and provide a cool feeling to the workers. Also, renovations were carried out by procuring cabinets as containers for storing finished tools and horseshoes.
The finished product can be placed in a cupboard or on the shelf according to its size. With cabinets, SMEs can apply the $5 \mathrm{~S}$ principle. Figure 16 shows the improvement in the horseshoe's SME condition before and after the work layout improvements.
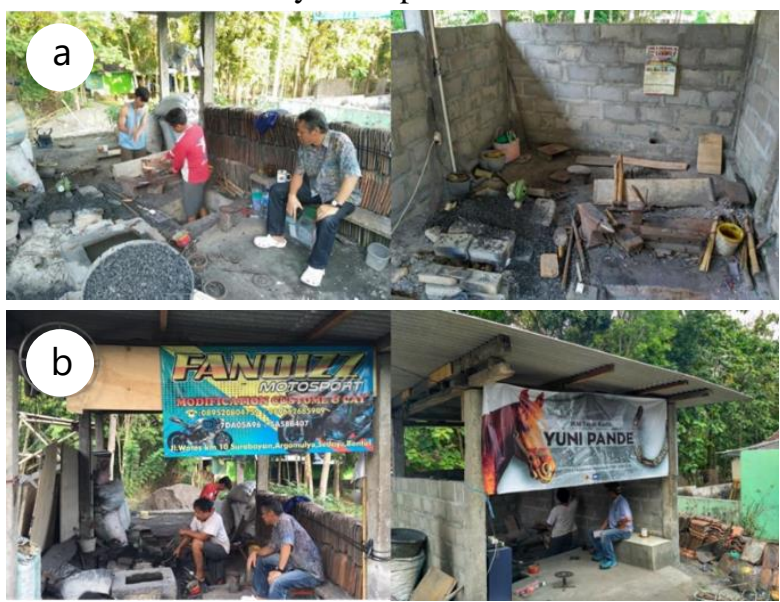

Figure 16. Comparison workplace of the horseshoe's SME: (a) before; and (b) after improvement

b. Improvement of work method

In order to support the increase in the quantity and quality of horseshoe products, improvements to the SME layout are not sufficient. They need to be supported by improvements in working methods. The initial process is still a conventional method of forging and cannot support standardized product quality. Therefore, to maintain and improve product standards, a new tool is designed for making horseshoe products (as shown in Figure 17). This tool can be used as a printing tool for horseshoe. By improving work layout and method, it will increase the productivity of SME and improve the quality of horseshoe products to make them more standardized.

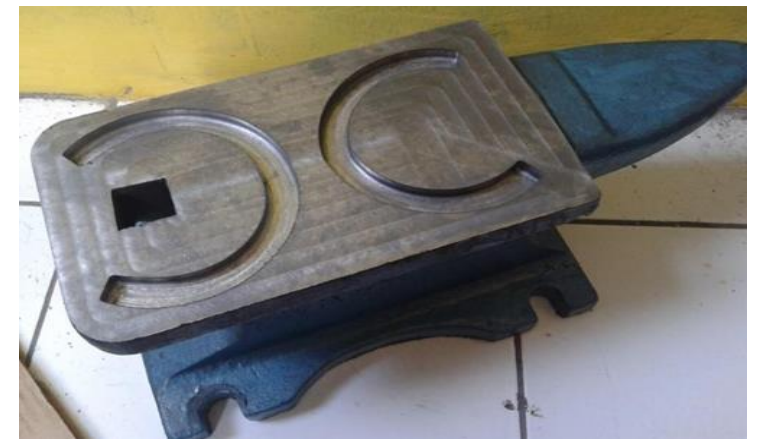

Figure 17. New tool for printing horseshoe

\section{CONCLUSION}

Based on several analyses, to solve the problem at Zero Kilometer Point (KM 0) of Yogyakarta City, especially in the slipping of andong horses, it was necessary to use the redesigned horseshoe, namely horseshoe with $40 \%$ rubber pads. This solution is considered to have increased the friction value by 0.54 (or $10 \%$ from the initial condition), and it can reduce the slipperiness 
level at KM 0. Moreover, this study also guided horseshoe SMEs by improving work layout and work method by implementing $5 \mathrm{~S}$ principles. It is hoped that the implementation of design A (with $40 \%$ rubber pads) and the guidance for horseshoe's SME can improve the quality, not only the quality of the horseshoe product but also the quality of SME production so that it can support the image of Yogyakarta as a tourist city.

\section{ACKNOWLEDGMENT}

This activity was funded by Universitas Gadjah Mada, especially from Community Service Grant of Engineering Faculty with No. 723/H1.17/H1.17/OT/2016 and Grant for Appropriate Technology Application of UGM Community Service Directorate with No. 298/DIT.PM/2016

\section{REFERENCES}

Agrahari, R.S., Dangle, P.A., Chandratre, K.V. (2015). Implementation Of 5S Methodology In The Small Scale Industry: A Case Study. International Journal of Scientific \& Technology Research, vol. 4, no. 4, pp. 180-187.

BOC. (2016, February 10). Principles Carburising and Carboniting. URL: https://www. Boconline.co.uk/internet.lg.lg.gbr/en/images/Pri nciples\%20of\%20Carburising\%20and\%20Carb onitriding410_114378.pdf.

krjogja.com. (2016, January 5). Kunjungan Wisatawan 2014 Lampaui Target. URL: http://krjogja.com/read/247646/kunjunganwisatawan-2014-lampaui-target.kr.

Kwietniewski, C.E.F., Tetrardini, E., dan Totten, G.E. (2013). Carburizing and Carboniting. Encyclopedia of Tribology, pp. 298-306.

Martin, L.A. (2014). Alternative Materials for the Horseshoe. University of Skövde, Swedia.

Schneider, M. J., dan Chatterjee, M. S. (2015). Introduction to Surface Hardening of Steels. ASM Handbook, Vol. 4A.

Solopos.com. (2016, January 5). Diduga Karena Jalan Licin, 2 Kuda Penarik Andong Terpeleset Di Titik Nol Kilometer. URL: https://www.solopos.com/diduga-karena-jalanlicin-2-kuda-penarik-andong-terpeleset-di-titiknol-kilometer-674007.

Wardhana, R. (2013). Pengaruh Lingkungan Kerja Terhadap Produktifitas Pekerja (Studi Kasus: Industri Kerajinan Gerabah Kasongan Bantul). Universitas Gadjah Mada, Yogyakarta. 

